\section{Human space flight}

SIR-The maxim quoted again by G. B. Field, M. J. Rees and D. N. Spergel in their otherwise excellent article (Nature 336, 725-726; 1988) that human spaceflights "cannot be expected to yield a return commensurate with their cost if the judgement is made in purely scientific terms" is objectionable.

We need look no further than the Viking missions to Mars to see the problems of trying to automate science. Even after the expenditure of $\$ 1,000$ million (more than $\$ 3,000$ million in current dollars), nobody knows today whether or not there is life on Mars. The Viking landers failed in the single purpose for which they were built. This is not to say that they did not serve other ancillary functions, but had the landers not been constructed around elaborate biology packages, the initial reconnaissance of Mars and its system could have been accomplished for a small fraction of what was actually spent.

We forget that the Viking missions were not inexpensive relative to manned flights. Typical modern estimates for the cost of sending people to Mars (which are little changed from those during the mid1970 s) range from an unrealistic low of $\$ 10,000$ million to a more likely $\$ 40,000$ million - only 3.3 to 13.3 time the $\$ 3,000$ million cost of Viking in current dollars. Can anyone seriously argue that putting a few intelligent and flexible human beings and their equipment on the martian surface for weeks (or for months or years) will result in only thirteen times Viking's scientific return?

Given the decisions that face the US space programme, a more relevant way to look at this issue is to consider that, even given the highest estimates for the true cost of launching a Spacelab shuttle mission (about $\$ 500$ million), the Viking expenditure would pay for no less than six Spacelab flights. Whichever way we measure it, even one Spacelab flight achieves far more science than did Viking. Does it not make sense to consolidate our position in the Earth-Moon system before we go gallivanting across the Solar System? Perhaps this could be done by building the much-maligned space station, which, in addition to laying the technological foundations for human planetary exploration, would admirably serve almost every field of space science but planetary exploration. The space station would extend all the advantages of Spacelab at a cost of only some eight times Viking.

The distinction between reconnaissance and science may seem fine, but I believe it is the natural division between what should be expected of automated spacecraft and what must wait for human exploration. The lesson of Viking is that, for the foreseeable future, automating creative science will at best be extremely expensive and difficult, and probably impossible - whether on Earth, in orbit or far across the Solar System. This is a lesson we should consider very carefully before spending vast sums of money $(\$ 16,000-10,000$ million is the current guess) on a Mars Rover which roves less far with every study, trying to automate what a human driver could do far better for only a few times the cost.

Automated missions are tremendously valuable for some limited applications. But human missions are necessary for most sciences beyond initial reconnaissance, and planetary scientists do themselves no favours by denying that.

DONALD F. ROBERTSON

940 Capp Street,

San Francisco, California 94110, USA

\section{The test of time}

SIR-I have wasted a lot of time in my life trying to reproduce astonishing results. I know of scientists who, on any subject, publish in parallel two or three competing interpretations or theories. And a few years ago I was amazed to hear a scientist prominent in my field disclaim five articles he had recently published. It is difficult to convey the resulting scepticism about the literature to young scientists without discouraging them.

I therefore propose that when a scientist is under consideration for a new post or for promotion, his or her publications list should be checked to see whether the findings and interpretations have stood the test of time and, if not, whether they have been retracted. This complements the Harvard rule whereby only positive evidence (the four best papers) is considered. This would uncover quite a few prominent researchers whose latest sensational work always seems to obscure past errors.

Université Libre de Bruxelles,

JACQUES E. DUMONT

Faculté de Médécine,

Campus Hôpital Erasme,

Route de Lennik, 808 ,

B-1070 Brussels, Belgium

\section{Rough justice}

SIR-William McBride has some valid comments in his letter on the inquiry into his alleged fraudulent conduct (Nature 336, 614; 1988). On the basis of his statement that he was not allowed legal representation, nor to attend all the hearings, nor to cross-examine witnesses, he did not receive natural justice.

The transcript of the inquiry is not publicly available and analysts have only the report to guide them. It seems that McBride should perhaps have been given the benefit of the doubt on having altered the oral dose rates because he believed he was correcting them in answer to a referee's comment. The report makes a convincing case for finding that $\mathrm{McBride}$ did not use "proper scientific method" (Report 25; 1988) in his work. This might explain his dubious method of corrections and his incorrect statements about controls. It seems, however, that there was "deliberate falsification" (Report 24; 1988) about the number of experimental rabbits.

The final version of McBride's paper, published by an Australian journal after its rejection by an overseas journal, should have been scrutinized more carefully by the referee in order to remove unsupported conclusions. Foundation 41 and its research advisory committee also performed badly, especially in their failure to investigate fully the staff allegations and to oversee remedial action.

G. F. HUMPHREY

School of Biological Sciences, University of Sydney,

Australia 2006

\section{Apoptosis}

SIR-In reply to B. Kleine (Nature 377, 402; 1989), J.F.R. Kerr et al. (Br. J. Cancer 26, 239-257; 1972) proposed the term "apoptosis" (suggested by Professor J. Cormack, Department of Greek, University of Aberdeen) for a process of active, programmed cell death with a number of characteristic features which clearly distinguish it from "necrosis", passive cell death. The standard Classical Greek-English dictionary (H. G. Liddell \& R. Scott, A Greek-English Lexicon, 6th Edn, Oxford University Press; 1869) defines $\alpha \pi \sigma \pi \tau \omega \sigma \iota \varsigma$ as "a falling off or away"; it is used of the falling of leaves, a clear example of programmed death. The cognate verb is, of course, the reduplicated form $\alpha \pi \sigma \pi i \pi \tau \omega$; $\alpha \pi \circ \pi \tau \omega \sigma \omega$, quoted by B. Kleine, is not known to this dictionary. A computer search of papers published since 1983 revealed fifty with "apoptosis" or "apoptotic" in the title. Had B. Kleine consulted A. H. Wylie et al. (J. Pathol. 142, 67-77; 1984), cited in our letter (Nature 337, 181-184; 1989), rather than his Greek-German dictionary, he would have found a clear exposition of the meaning of apoptosis.

CHRISTOPHER A. SMITH GWYN T. WILLIAMS ROSETTA KINGSTON ERIC J. JENKINSCN JOHN J. T. OWEN

Department of Anatomy,

The Medical School,

University of Birmingham,

Birmingham, B15 2TJ, UK 